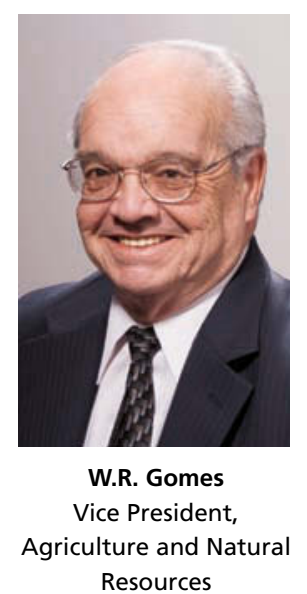

Resources

\title{
Taking the university to the people
} Tanuary is named after the Roman
God Janus - the keeper of gates, the
God of beginnings. Janus is depicted in Roman culture as simultaneously looking forward and backward, for each beginning is based on developments of the past.

When I arrived at UC in 1995, UC President Jack Peltason asked me to develop a mission statement for ANR, to examine the administrative structure of the organization, and to plan for the new millennium. As I retire in 2007, UC President Robert Dynes has asked me to reflect upon the changes that have occurred and to summarize the few that give me the greatest source of pride. Because this January marks my last editorial before retirement, I'd like to share my responses with you.

I'm proud of the cultural changes that have taken place in our division. Driven by a need to serve a rapidly changing industry in a rapidly changing state, we now emphasize emerging issues in agriculture, natural resources and human sciences and position ourselves to address these needs. While we continue to serve broadly based stakeholders, we no longer focus on discipline-oriented and geographically defined goals. Rather, our decisions and directions are designed to address those areas where we can make the greatest difference.

To effect this change, we started with a strategic plan based on a mission, articulated by a vision and tempered by core values that ANR as a unit enumerated. The plan was developed with input from a wide range of sources and reflection from many thoughtful people. Designed to be dynamic, it outlined criteria for determining program priorities that could serve as the basis for virtually all future decisions; the plan was not a road map, but a compass.

In the current climate of change and quest for adherence to the highest and strictest standards, it is gratifying to note that we - as an organization - embraced ethical behavior as the first of our core values.

From our planning process came a set of strategic assumptions, mid- and long-term program priorities, and an in-depth look at our organizational structure. At the urging of many of our stakeholders, we developed a new structure that emphasized divisionwide planning, installed program leaders and rejuvenated workgroups, among other changes designed to emphasize opportunities and address issues.

To help position our programs for 21st-century California, we asked distinguished UC scientists to think about the longterm future (the next 25 years) of California's agricultural, natural and human resources for special editions of California Agriculture to be published in the millennial year. The fourpart collection - on population, resources, food production and food security - (Vol. 54, Nos. 1, 2, 4 and 5) continues to provide a strong basis for our thinking.
I'm proud of our people. My 11 years at UC have been a rich time of working with a cadre of gifted academics, dedicated staff and insightful administrators.

During the later 1990s, we began developing plans for the renewal of our programs that had been decimated by the budget cuts of the early 1990s. Our people looked forward: rather than trying to reclaim lost "turf," they anticipated new opportunities and directions. The cooperative atmosphere was inspiring.

When the budgetary axe fell again a few years later, we were subjected to all of the negatives: program closures, layoffs, frozen positions, redirection of carefully saved funds. But, overall, we retained our perspective, embraced our priority-planning process, minimized our hand-wringing and finger-pointing, and responded positively to adversity. This is a tribute to all of our people on the campuses, in the counties, and in ANR offices based in Oakland, Davis, Kearney and Riverside.

I'm proud of the increased visibility that our people and programs have gained in the system, on the campuses and with the public. With the cooperation of UC Presidents Richard Atkinson and Robert Dynes, we demonstrated to them and others many of the important programs that the University conducts throughout the state. After members of the UC Board of Regents walked through the lettuce fields and packing plants of the Salinas Valley, they better understood the issues surrounding Escherichia coli and Salmonella outbreaks; after viewing the limited damage of Pierce's disease in the Napa Valley, they could address the devastation later wrought by the appearance of the glassy-winged sharpshooter.

When President Dynes introduced his concept of "Research-Development-Delivery" to the university community, we were able not only to demonstrate "R, D \& D" in action, but also a system of delivery that is unparalleled.

As UC wrestles with issues of diversity, we are able to showcase nutrition, after-school and youth programs that reach African-American, Latino, Hmong, Vietnamese and other underserved populations. Legislators from Sacramento and Washington and visitors from around the world have been able to see that we truly take the university to the people - all of the people.

President Atkinson expanded the dialogue with our stakeholders by establishing the UC President's Advisory Commission on Agriculture and Natural Resources. Both he and President Dynes have worked hand-in-hand with California leaders to identify the issues, foresee the direction of California's resources and define the University's role in addressing them. The relationship between the University and the industry is strong.

I'm proud to have served UC. Several of you have asked what I will be doing after retirement. I might go fishing. Anne and I will travel and spend time with our children and extended families. I don't know how much - or how little - I'll be involved in ANR issues, but a part of my heart will always be with the University of California. 